San Jose State University

SJSU ScholarWorks

Master's Theses

Master's Theses and Graduate Research

Summer 2014

\title{
The Response of Bats to Introduced Trout in Naturally Fishless Lakes Sierra Nevada, California
}

Elizabeth Gruenstein

San Jose State University

Follow this and additional works at: https://scholarworks.sjsu.edu/etd_theses

\section{Recommended Citation}

Gruenstein, Elizabeth, "The Response of Bats to Introduced Trout in Naturally Fishless Lakes Sierra Nevada, California" (2014). Master's Theses. 4465.

DOI: https://doi.org/10.31979/etd.85md-hecd

https://scholarworks.sjsu.edu/etd_theses/4465

This Thesis is brought to you for free and open access by the Master's Theses and Graduate Research at SJSU ScholarWorks. It has been accepted for inclusion in Master's Theses by an authorized administrator of SJSU ScholarWorks. For more information, please contact scholarworks@sjsu.edu. 
THE RESPONSE OF BATS TO INTRODUCED TROUT IN NATURALLY FISHLESS LAKES OF THE SIERRA NEVADA, CALIFORNIA

\author{
A Thesis \\ Presented to \\ The Faculty of the Department of Biological Sciences \\ San José State University \\ In Partial Fulfillment \\ of the Requirements for the Degree \\ Master of Science \\ by \\ Elizabeth Gruenstein
}

August, 2014 
(C) 2014

Elizabeth Gruenstein

ALL RIGHTS RESERVED 
The Designated Thesis Committee Approves the Thesis Titled

THE RESPONSE OF BATS TO INTRODUCED TROUT IN NATURALLY FISHLESS LAKES OF THE SIERRA NEVADA, CALIFORNIA

by

Elizabeth Gruenstein

APPROVED FOR THE DEPARTMENT OF BIOLOGICAL SCIENCES

SAN JOSÉ STATE UNIVERSITY

August 2014

Dr. Shannon Bros-Seemann

Dr. David S. Johnston

Dr. Luis A. Bonachea
Department of Biological Sciences

H.T. Harvey \& Associates

Department of Biological Sciences 


\section{ABSTRACT \\ THE RESPONSE OF BATS TO INTRODUCED TROUT IN NATURALLY FISHLESS \\ LAKES OF THE SIERRA NEVADA, CALIFORNIA}

\section{by Elizabeth Gruenstein}

Stocking of trout into naturally fishless water bodies in the mountains of western North America has reduced populations of many native species in those systems, with benthic aquatic invertebrates being particularly impacted. Although bats are known consumers of emergent aquatic insects, almost no studies have focused on how changes to these prey populations at lakes subsequent to trout stocking could affect them. This study assessed bat activity, foraging activity, and foraging rate at nine feature-matched pairs of stocked and unstocked high elevation lakes in the central Sierra Nevada mountains in an effort to determine which provide higher quality foraging habitat for bats. Bats in the $25 \mathrm{kHz}$ and $50 \mathrm{kHz}$ echolocation call categories showed little to no behavioral change between lakes with trout and lakes without. In contrast, bats in the $40 \mathrm{kHz}$ group had higher levels of activity at stocked lakes, which may indicate that at those lakes bats are consuming numerous small insects. If this is the case, it could represent a cost to those bats due to the lower energetic return of small prey items compared to the preferred prey species. 


\section{ACKNOWLEDGEMENTS}

I am deeply indebted to a number of people who supported me during this project. I am lucky enough to have committee members who have become friends as well as mentors. Dave Johnston introduced me to the world of bats and has been unfailingly generous and enthusiastic during each phase of my study. His good humor during setbacks and deep knowledge of bat biology pushed me to set higher standards for myself. Shannon Bros-Seemann spent countless hours helping me develop my ideas, painstakingly crafting statistical models and re-teaching me statistics, and showing me the path to being a good scientist. This project would never have gotten off the ground if not for her guidance and care. Luis Bonachea reinvigorated my love for animal behavior and evolution, was a friend during crises, and brought tremendous energy to editing the written portion of this project.

I would never have been able to take equipment deep into the Sierra backcountry without the friends who spent days of their time carrying it there. Cassie Gruenstein, Dana Terry, Dave Johnston, Veronica Wunderlich, Tom Hirst, Scott Elkins, Ivy Lurz, Ma'ayan Bresler, Chris Terry, Carey Terry, and Daniel Johnston saw me through bears, mosquitoes, getting lost, equipment failure, crises of conscious, and many long miles up and down mountains (sometimes in the dark). I am extremely grateful to all of them for their endless good cheer, common sense, confidence in my abilities, and willingness to keep going.

My study also benefited from the help of other researchers, experts in the field, and staff members of the state and federal agencies with which I worked. Pete Epanchin and Karen Pope did studies that helped lay the groundwork for mine, and also spent time speaking to me on the phone about their research. Roland Knapp has worked for years on the issue of introduced trout in the Sierra Nevada and was generous enough to share data 
and ideas with me. Bill Rainey contributed to my study design, and his past research on bats of the Sierra Nevada provided invaluable information. Tracy Allen performed a vital service by repairing my bat detectors when they malfunctioned. Sarah Stock, Lindsay Cline, Travis Espinosa, and Les Chow at Yosemite National Park, Marcie Baumbach and Linda Angerer at Stanislaus National Forest, and Sarah Mussulman at the California Department of Fish and Wildlife were kind and patient while helping me through the labyrinthine process of obtaining permits and equipment, providing me with much-needed information, and responding to my endless requests for data.

My work also benefited from other sources, notably the North American Society for Bat Research and the Western Section of the Wildlife Society who gave me with opportunities to present during various phases of this project. In addition, Steve Powell, Hilary Hodge, Cullen Wilkerson, and Jill Grant at BioMaAS Inc. enabled me to maintain employment while providing the flexible schedule that I needed, along with support and commiseration.

My family is a never-ending source of encouragement and care. My in-laws, the Terry family, were always interested in what I was doing and cheered me on. My brother Alex and his wife Anna supported my aspirations and reminded me of the value of good research, and with help from their kids Elise and Oliver generously fed and played with me while letting me sleep at their house so I could avoid the long commute. My sister Cassie hauled equipment up a mountain, rescued me with tea and walks during the long writing process, and never let me get too down on myself. My parents, who I cherish, have always encouraged my dreams of studying wildlife, comforted and praised me during the difficult parts of this project, and gave much-appreciated financial and editorial assistance. Last, my 
beloved husband Dana shored me up in every way when my strength failed, and also was the one to inspire me to study bats in the first place. I love you and could not have done this without you. 


\section{TABLE OF CONTENTS}

List of Figures




\section{LIST OF FIGURES}

Figure 1. Typical call sequence included in the $50 \mathrm{kHz}$ echolocation category............6

Figure 2. Typical call sequence included in the $40 \mathrm{kHz}$ echolocation category............ 7

Figure 3. Typical call sequence included in the $25 \mathrm{kHz}$ echolocation category............. 7

Figure 4. Typical call sequence included in the $10 \mathrm{kHz}$ echolocation category.............8

Figure 5. A bat call sequence with two feeding buzzes (shown in boxes), which indicate foraging attempts.

Figure 6. Results from 3-way ANOVA: The significant stocked*phonic interaction for the total activity of bats at surveyed lakes.

Figure 7. Results from planned comparisons: Time period effect for the total activity of bats at surveyed lakes. 15

Figure 8. Results from 3-way ANCOVA: The significant stocked* phonic group interaction for foraging activity of bats at surveyed lakes

Figure 9. Results from 3-way ANCOVA: The significant phonic group * time period interaction for foraging activity of bats at surveyed lakes.

Figure 10. Results from 3-way ANOVA: The significant stocked * phonic group interaction for foraging effort of bats at surveyed lakes. 


\section{LIST OF TABLES}

Table 1. 3-Way ANOVA for the total activity of bats at surveyed lakes......................... 12

Table 2. 3-Way ANCOVA for the foraging activity of bats at surveyed lakes. ............... 16

Table 3: 3-Way ANOVA for the foraging effort of bats at surveyed lakes....................... 19

Table 4: ANCOVA for the ratio of small $(<3 \mathrm{~mm})$ Dipterans to larger aquatic insects caught at lakes with and without stocked trout. ................................................................ 22

Table 5: Capture frequencies for three orders of insects at stocked and unstocked lakes. 


\section{Introduction}

Stocking of trout into naturally fishless water bodies in the mountains of western North America has had profound negative impacts on native species diversity and trophic exchange in these systems (Bahls,1992; Finlay \& Vredenburg, 2007; Knapp, 1996). Many organisms with aquatic life stages, such as amphibians and emergent aquatic insects, have experienced population declines as a result of predation by trout (Knapp \& Matthews, 2000; Pilliod \& Peterson, 2001; Pope et al., 2009; Tyler et al., 2008). Consequently, terrestrial predators that rely on prey from aquatic ecosystems are likewise affected, including spiders (Benjamin et al., 2011), garter snakes (Lawler \& Pope, 2006; Matthews et al., 2002), and the gray-crowned rosy-finch (Leucosticte tephrocotis dawsoni), a bird that nests at high elevations (Epanchin et al., 2010).

Among prey species, the abundance, diversity, and biomass of benthic aquatic invertebrates are particularly impacted by the introduction of trout (Finlay \& Vredenburg, 2007; Knapp et al., 2001; Pope et al., 2009). In the Sierra Nevada, Knapp et al. (2001) found significantly lower numbers of most orders of invertebrates at lakes with fish compared to those without, including the emergent aquatic insects such as mayflies (Ephemeroptera) and caddisflies (Trichoptera). Pope et al. (2009) showed that removing trout from lakes in the Trinity Alps Wilderness increased the abundances of emerging Ephemeroptera and Trichoptera, as well as overall insect biomass. In these studies, the only prevalent insects that were found in higher abundance at stocked lakes were small dipterans, particularly midges (Chironomidae) and mosquitos in the genus Culex, the larvae of which avoid being eaten by trout due to their small size and which also 
experience lowered predation pressure as fish reduce populations of larger, predatory insects.

Although many bat species are known consumers of aquatic emergent insects, almost no studies have focused on how declines in insect abundance, diversity, and biomass at lakes subsequent to trout stocking could affect them. While Lawler and Pope (2006) reported impacts to amphibians and other taxa from stocked trout, acoustic bat activity data they also collected has not been published (Karen Pope, pers. comm., January, 2011). High-elevation ecosystems are resource limited, and seasonal pulses of emergent aquatic insects make up a large part of their overall productivity (Epanchin et al., 2010; Finlay \& Vredenburg, 2007). For the bats in these habitats that depend on subsidies of insects from the lentic environment, trout stocking in lakes could cause a loss of high-quality foraging habitat (Joseph et al., 2011; Lawler \& Pope, 2006; Pope et al., 2009).

Bats have been shown to respond to other modifications of aquatic habitats, especially those that result in changes to insect emergence (e.g., Fukui et al., 2006). Pipistrellus pygmaeus is more active in naturally vegetated riparian zones than in those disturbed by agricultural activities (Scott et al., 2010), and emergent insect specialists Pipistrellus pipistrellus, Myotis daubentonii, and Perimyotis subflavus forage differently upstream and downstream of sewage outputs (Abbott et al., 2009; Kalcounis-Rueppel, 2007; Vaughan et al., 1996). However, changes to a system may not always result in a negative effect; for example, when a bat's prey base includes insects that thrive in eutrophic conditions, the introduction of sewage into a river could potentially increase the 
river's value as foraging habitat for that species (Abbott et al., 2009; Vaughan et al., 1996).

Bats that experience a reduction in insect prey base after trout stocking could suffer energetic costs as a result of being required to forage for longer time periods or fly further distances to find suitable prey, which would especially impact bats that are raising young, as several species do at high elevations. In Yosemite National park, Myotis lucifugus are found breeding almost exclusively above 2,000 meters (Pierson et al., 2001). During maternity season (May-August) when females of this species are lactating, they shorten their average foraging distance so that they can return to a roost to nurse non-volant young several times during a night; Henry et al. (2002) documented a $42 \%$ decrease in range size after pregnant Myotis lucifugus gave birth and started lactating (from an average of 30 hectares to 17.6 hectares). A lack of suitable foraging habitat near a preferred roost would require females to expend more energy foraging and perhaps spend less time nursing than they would otherwise, which in turn could result in poor body condition for mothers or offspring (Kurta et al., 1989).

In this study, bat activity, foraging activity, and foraging rate were assessed at Sierra Nevada lakes with and without stocked trout to determine which provides higher quality foraging habitat for the various species of bats in these mountains. At least 11 species of bats are commonly found in the Sierra Nevada above 2,000 meters (Pierson et al., 2001), and they have a wide variety of diets and foraging strategies. I predicted that it would be the bats that are reliant on emergent aquatic insects that would show a response to the presence of trout in a lake; they include primarily two species (Myotis lucifugus 
and M. yumanensis, whose small size restricts their diet to smaller prey, and who echolocate at higher frequencies $(40-50 \mathrm{kHz})$. Larger bats that call at lower frequencies (8-30 kHz) can take a wider variety of prey items, including large prey (such as moths), and so may be less impacted by changes to the emergent aquatic insect population (Waters et al., 1995). Bats that respond to trout stocking could exhibit different levels of foraging activity over lakes with trout than over those without, or they might change the timing of their activity throughout the night either as a result of energetic stress (Duverge et al., 2008) or in response to a shift in peak insect activity. They may also show a difference in foraging rate, indicating that they are varying their diet to account for shifts in insect availability (Abbott et al., 2009; Akasaka et al., 2009; Kalcounis-Rueppel, 2007; Scott et al., 2010; Vaughan et al., 1996).

\section{Method}

In July of 2012 and 2013, bat echolocation calls were recorded at 18 lakes, nine with stocked trout and nine without trout, in the central Sierra Nevada mountains. Lakes and streams above 1800 meters in the Sierra Nevada were historically fishless (Bahls, 1992; Pilliod \& Peterson, 2007), but stocking of non-native trout (mostly rainbow trout Oncorhynchus mykiss, golden trout - O. m. aguabonita, and brook trout - Salvelinus fontinalis) in Sierran lakes and streams started in the late 1800s to provide food and recreation for European settlers (Pister, 2001). Stocking ceased entirely in national parks in 1991 but has continued in national forests; many watersheds within national parks and throughout the Sierra Nevada support sizeable trout populations (Knapp 1996, Pilliod and 
Peterson 2007). In the first season (July 2012), the study lakes were located in the northwest corner of Yosemite National Park. In the second season (July 2013), the sites were located in the southwest corner of the Emigrant Wilderness in Stanislaus National Forest.

One complication in assessing differences in bat activity is that variables that are not related to prey abundance, such as weather, proximity to roosting habitat, and nearby vegetation and landscape features can influence bat behavior in an area (Downs \& Racey, 2006; Erickson \& West, 2002; Furlonger et al., 1987, Hagen \& Sabo, 2011; Hayes, 1997). To reduce as much variation as possible, a block design was used with featurematched pairs (one with trout, one without) of lakes as blocks (Hayes, 1997; Seidman \& Zabel, 2001). Lakes were paired based on elevation, location, area, and depth, and partner lakes were surveyed simultaneously to reduce the impact of temporal variability. Paired lakes were no more than two kilometers apart. Study lakes were small (0.2 - 1.8 ha) and located in in granite basins surrounded by conifers, meadows, and rock features. All of the sites were between 1800 and 2700 meters above sea level, which places them between the lower montane and upper montane forest zones (Storer et al., 2004). Lake locations, fish status data, and some variables assessed for covariance (lake depth, lake area, and lake perimeter) were provided by the Division of Resources Management and Science of Yosemite National Park, the North Central Region of the California Department of Fish and Wildlife, and the Mi-Wok Ranger District of Stanislaus National Forest. Other potential covariates (the distance from the lake to the nearest river, the 
distance from the lake to the nearest lake, and the and the distance from the lake to the nearest water feature) were computed with Google Earth ${ }^{\mathrm{TM}}$ (2013).

For each lake, bat echolocation calls sequences were classified into four phonic groups based on the characteristic call frequency (Figures 1-4) (Keinath, 2004; Pierson et al., 2001; Szewczak et al., 2008). Calls were recorded using Anabat II ${ }^{\mathrm{TM}}$ detectors and Zero-crossings Analysis Interface Modules (Z-CAIM) ${ }^{\mathrm{TM}}$ recorders (Titley Electronics, Ballina, New South Wales, Australia), and call data were extracted with CF Read $4.4 \mathrm{~s}^{\mathrm{TM}}$ and processed using AnalookW 4.1b $\mathrm{b}^{\mathrm{TM}}$ (Titley Electronics, http://www.titleyscientific.com/us/index.php/software_firmware), which creates a file showing an acoustic frequency $(\mathrm{kHz})$ by time display (O'Farrell et al., 1999). After visual assessment of each file, call sequences were labeled according to their phonic grouping and those labels were extracted into a text file using the Anabat utility Dataget (after Miller 2001, available at http://www.msb.unm.edu/mammals/batcall/html/software.html).

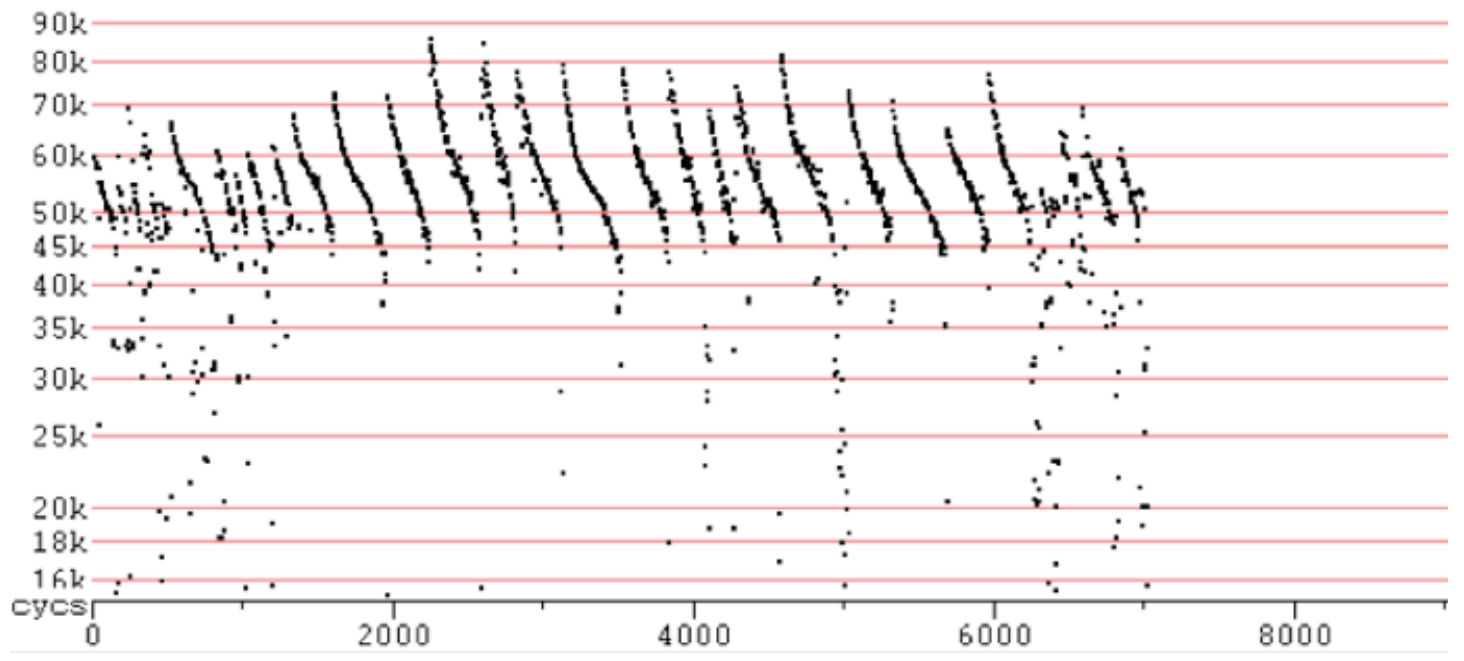

Figure 1. Typical call sequence included in the $50 \mathrm{kHz}$ echolocation category. Bats in this category include Myotis californicus and Myotis yumanensis, which echolocate at characteristic frequencies of 45-50 kHz. 


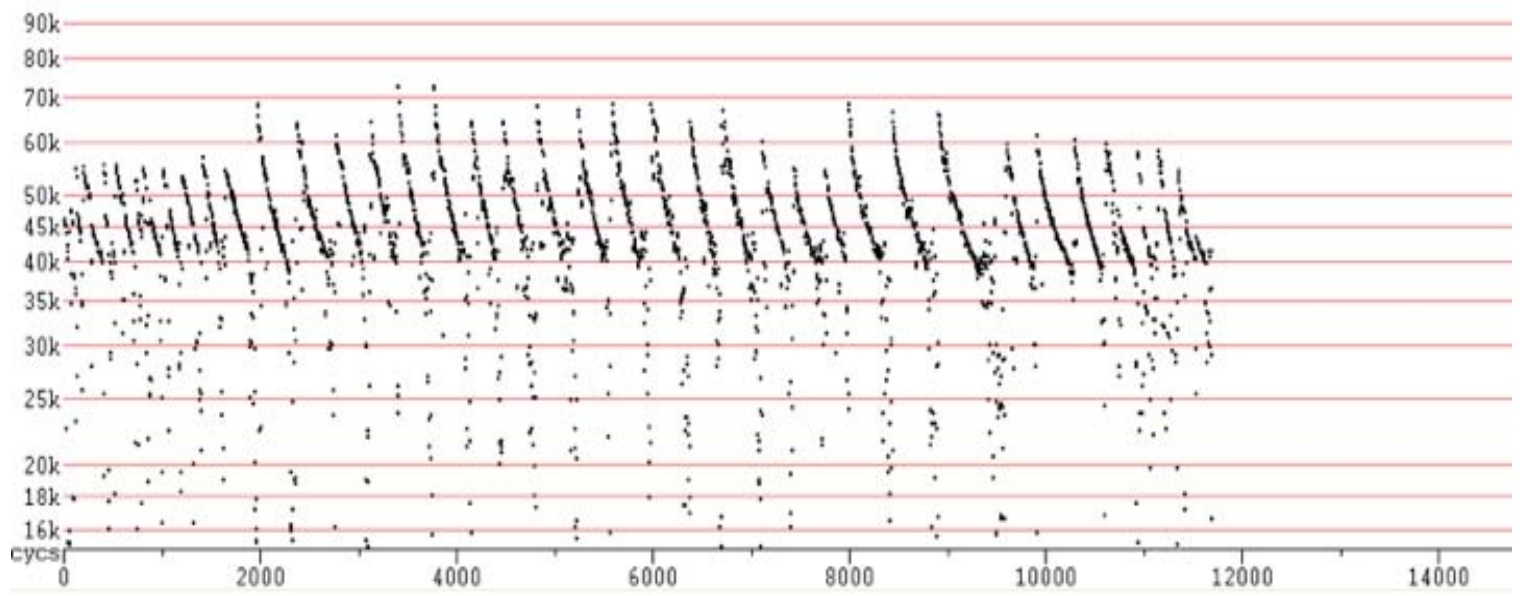

Figure 2. Typical call sequence included in the $40 \mathrm{kHz}$ echolocation category. Bats in this category include Myotis lucifugus and Myotis ciliolabrum, which echolocate at characteristic frequencies of 35-40 kHz.

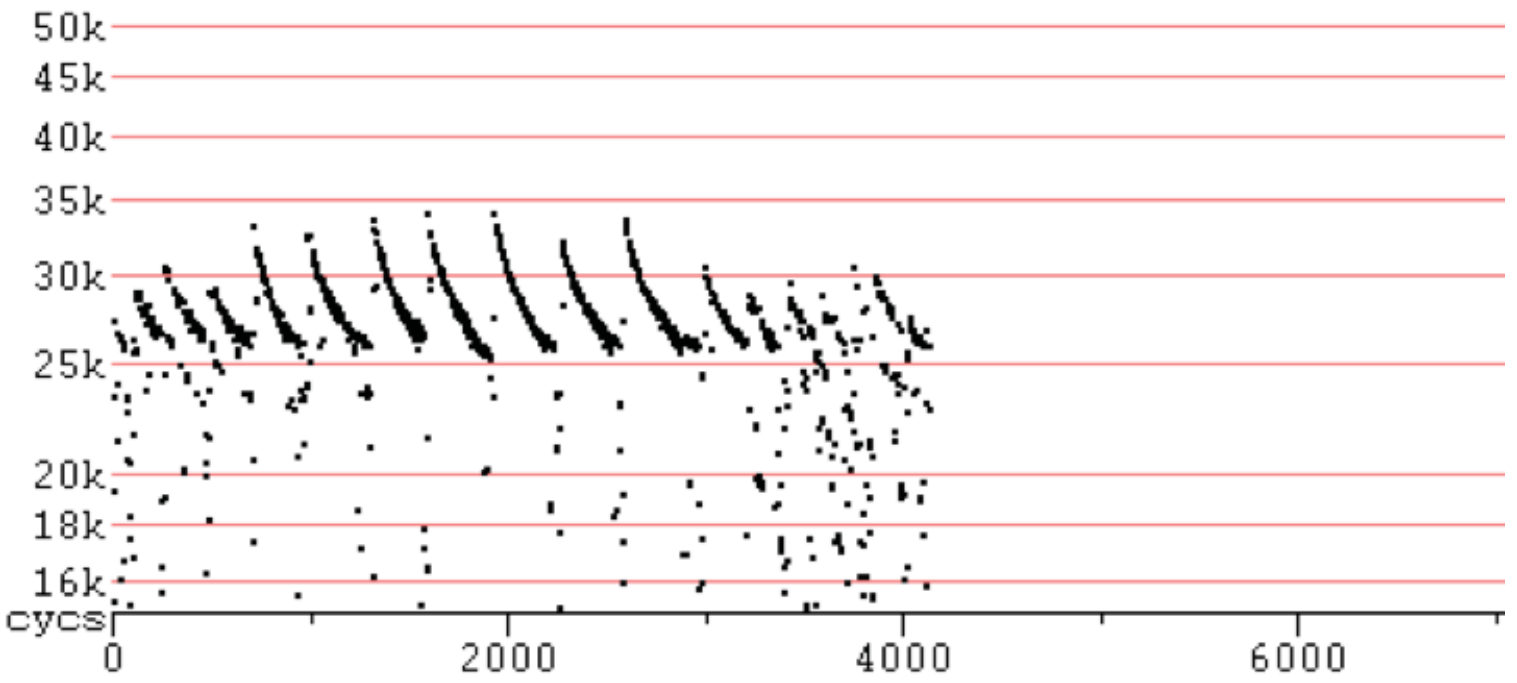

Figure 3. Typical call sequence included in the $25 \mathrm{kHz}$ echolocation category. Bats in this category include Eptesicus fuscus, Lasiurus cinereus, Lasionycteris noctivagans, Tadarida brasilienses, and Myotis evotis, which echolocate at characteristic frequencies of $20-30 \mathrm{kHz}$. 


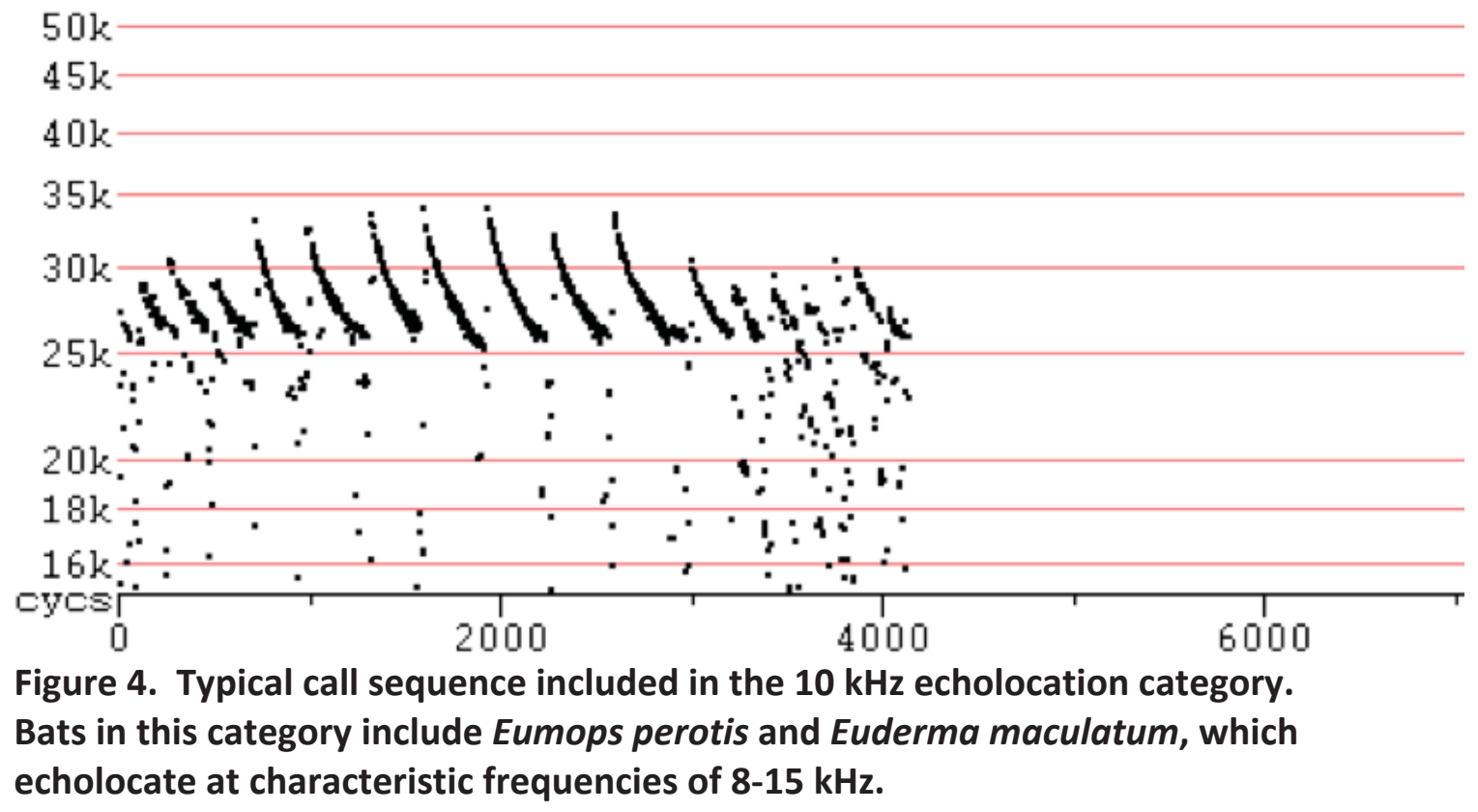

Bat activity was recorded throughout the night and was then organized into three time periods: Early (1900 - 2300 hours), Mid (2300 - 0300 hours), and Late (0300 - 0600 hours), in order to compare activity levels of each phonic group at different times of the night. Survey nights were July 11, 12, 13, and 27 in 2012 and July 12, 13, 25, 26, and 27 in 2013. During each survey night, bat detectors were placed at the four cardinal directions at both lakes in a given pair. Bat activity was recorded from the evening placement (usually an hour before sunset, but occasionally later) to the morning, when the detectors were collected. Data collected on nights with low temperatures, high wind speeds, and/or heavy precipitation were discarded and the area resurveyed as recommended by Hayes (1997) and Erickson and West (2002). The acoustic activity index described in Miller (2001) was used to reduce the chance of over- or underestimating the activity of a given species; a survey period is separated into 1-minute 
blocks and then overall bat activity is defined as the number of minutes in a survey period that contain at least one echolocation call sequence. Echolocation call sequences are defined as a series of two or more consecutive echolocation clicks produced by a bat as it flies within range of the detector (Fenton, 1977; Hayes, 1997; Johnston, 2002). Foraging activity was identified by visually assessing Analook files for the presence of foraging attempts known as "feeding buzzes" (Figure 5) which are identified as sequences in which echolocation clicks come closer and closer together as a hunting bat zeroes in on its prey (Griffin et al., 1960, Johnston 2002). Foraging effort was computed by comparing the ratios of foraging activity to overall activity (feeding buzzes per unit of activity) between treatments and among time periods and phonic groups.

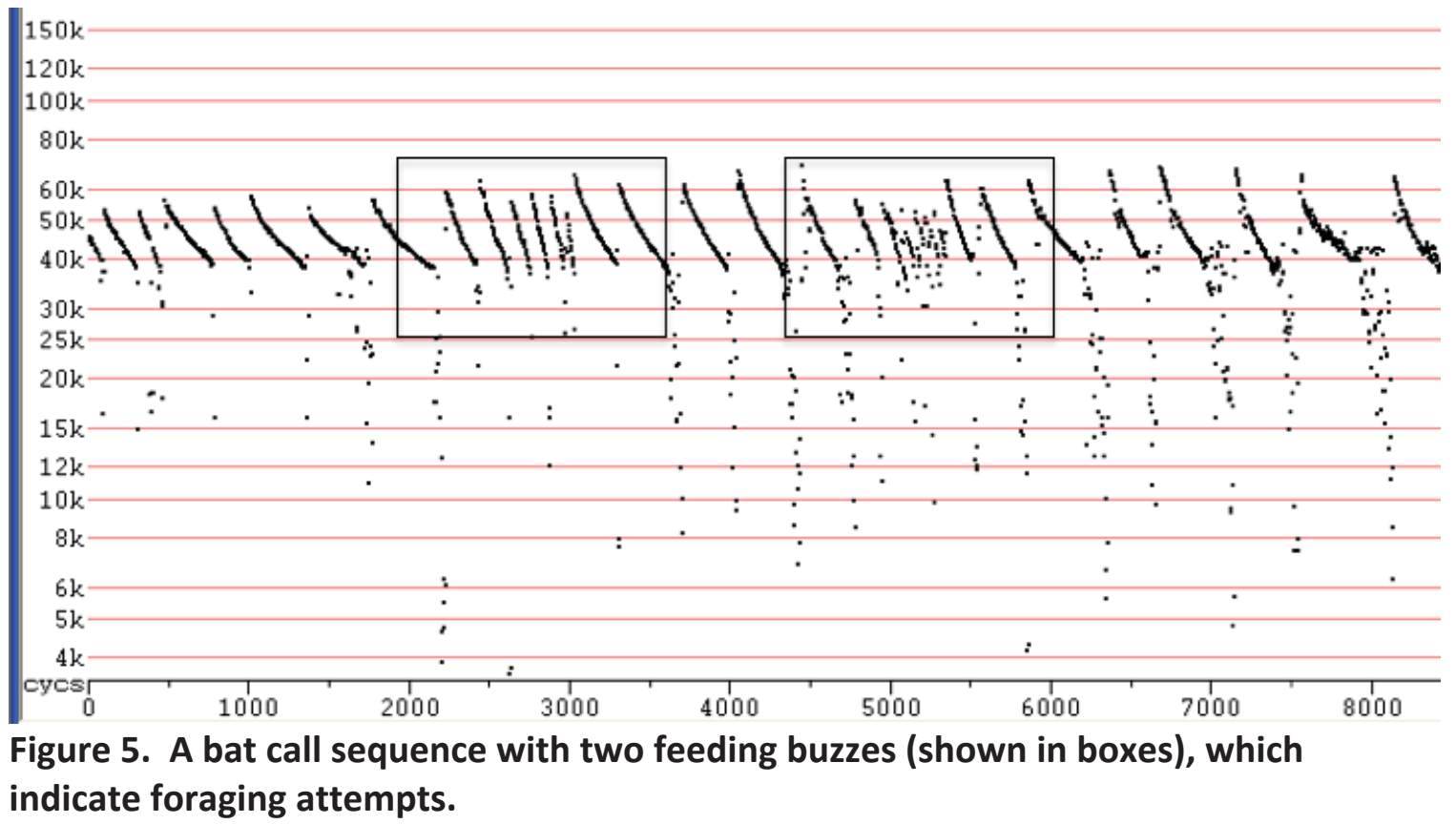


For each of the three dependent variables (overall bat activity, foraging activity, and foraging effort), a three way ANCOVA or ANOVA (Zar, 1999) was used to determine if a significant difference in the dependent variables existed among phonic groups, time period of activity, and whether or not lakes were stocked. The independent variables were trout stocking (Yes/No) and time period (Early, 1900-2300 hours; Mid, 1300-0200 hours; and Late, 0200-0500 hours). Each pair was considered a block. The measured variables were number of minutes of overall activity and the number of minutes of foraging activity. A two-way ANCOVA was used to analyze sets of data for which significant covariates were present, and a two-way ANOVA was used where no covariates were found to have significant effects. The variables assessed for covariance were lake depth, lake area, lake perimeter, the distance from the lake to the nearest river, the distance from the lake to the nearest lake, and the distance from the lake to the nearest water feature (whether a river or lake). Levene's tests were conducted for each ANOVA or ANCOVA to test for the assumption of homogeneity of variance; for all tests the pvalue was greater than 0.05 .

Invertebrate populations were assessed to evaluate the potential prey base for bats and to see whether the lakes reflect the overall trend of changes to invertebrate populations. Insect traps were placed at the lakes at the same times and roughly the same locations as the bat detectors and collected in the morning when detectors were collected. In 2012, I used floating emergence traps (Epanchin et al., 2010; Rainey. 2006,), and in 2013 switched to sticky traps (Collier \& Smith 1994). Emergence traps were round, floating $0.25 \mathrm{~m}^{2}$ traps constructed of wire, bicycle tubes, and $0.3 \mathrm{~mm}$ white mesh. Sticky 
traps were constructed of one $8.5 \times 11$ inch transparency sheet bent into a cylindrical shape and covered with liquid Tangle Trap (Tanglefoot, Grand Rapids, MI). Insects in these traps were collected, identified to order (Bland, 2010) and preserved in 70\% ethanol. To determine if the relative abundances of insect orders at the stocked and unstocked lakes reflected trends found in other studies, differences in the ratio of small $(<3 \mathrm{~mm})$ to large $(>3 \mathrm{~mm})$ insects were assessed using an ANCOVA. The independent variable was trout stocking (Yes/No). Lake depth, lake area, lake perimeter, the distance from the lake to the nearest river, the distance from the lake to the nearest lake, and the distance from the lake to the nearest water feature (whether a river or lake) were included as covariates.

\section{Results}

In 18 survey nights (nine total nights, two lakes per night) 7889 minutes of bat activity, with 4249 minutes of foraging activity, were recorded within three phonic groups of bats. Calls from bats in the $10 \mathrm{kHz}$ group were recorded at nearly every lake, and audible echolocation calls (most likely from spotted bats, E. maculatum) were routinely heard over study areas; however, the number of calls was insufficient for analysis.

A three-way ANOVA indicated that the three phonic groups responded differently in total activity between lakes with and without stocked trout and total bat activity differed among the three time periods (Table 1). 
Table 1. 3-Way ANOVA for the total activity of bats at surveyed lakes.

\begin{tabular}{|c|c|c|c|c|c|}
\hline Source & $d f$ & lean Square & $F$ & $p$-value & Observed Power \\
\hline Stocked & 1 & 34002.525 & 17.658 & N/A & .987 \\
\hline Phonic Group & 2 & 10807.265 & 5.612 & $\mathrm{~N} / \mathrm{A}$ & .852 \\
\hline Time Period & 2 & 18072.025 & 9.385 & $<.001$ & .977 \\
\hline Early and Late vs. Mid & 1 & 12970.679 & 6.736 & .010 & .731 \\
\hline Early vs. Late & 1 & 23173.370 & 12.034 & .001 & .931 \\
\hline Lake Pair & 8 & 11370.224 & 5.905 & $<.001$ & 1.000 \\
\hline Stocked * Phonic Group & 2 & 19487.080 & 10.120 & $<.001$ & .984 \\
\hline Phonic Group * Time & 4 & 3153.191 & 1.637 & .168 & .493 \\
\hline \multicolumn{6}{|l|}{ Period } \\
\hline Stocked $*$ Time Period & 2 & 649.358 & .337 & .714 & .103 \\
\hline \multicolumn{5}{|l|}{$*$ Time Period } & .344 \\
\hline Error & 136 & 1925.629 & & & \\
\hline
\end{tabular}

Note: Dependent variable is the number of minutes of activity (minutes with echolocation call sequences recorded). Independent variables are stocked (yes or no), phonic group ( $25 \mathrm{kHz}, 40 \mathrm{kHz}$, and $50 \mathrm{kHz}$ ), and time period (Early: 1900 - 2300, Mid: 2300 - 0200, Late: 0200-0500). The two planned comparisons for Time Period are included: Early and Late versus Mid, and Early versus Late. Lake pair was used as a block. Lake depth, area, perimeter, and the distance of the lake to the nearest river were initially included as covariates, but were not significant and were not included in final analysis. Significant $p$-values are emphasized in bold italics.

The significant stocked and phonic group interaction $(F=10.120, d f=2, p<.001)$

indicated that the three phonic groups of bats reacted in different way to the stocking of lakes; bats in the $40 \mathrm{kHz}$ phonic category had considerably more activity at lakes where stocked trout are present, the $50 \mathrm{kHz}$ phonic group showed a slight increase at stocked lakes, and the $25 \mathrm{kHz}$ group showed almost no difference (Figure 6). 


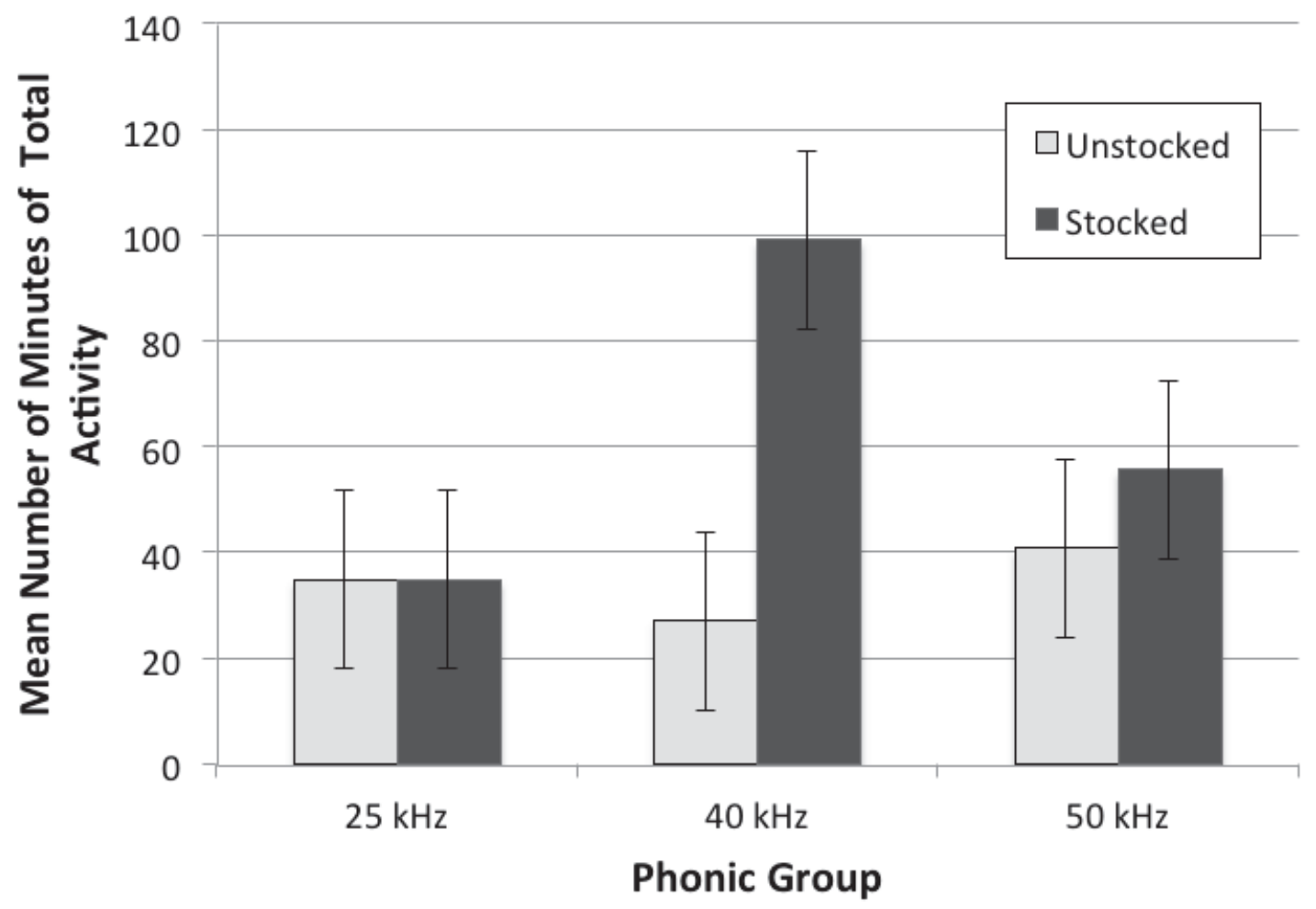

Figure 6. Results from 3-way ANOVA: The significant stocked*phonic interaction for the total activity of bats at surveyed lakes.

The dependent variable is the number of minutes of activity (minutes with echolocation call sequences recorded). Independent variables are stocked (yes or no) and phonic group ( $25 \mathrm{kHz}, 40 \mathrm{kHz}$, and $50 \mathrm{kHz}$ ). Lake pair was used as a block. Confidence bars are $95 \%$.

The non-significant Stocked*Time Period*Phonic Group interaction implied that the responses of the three phonic groups to stocking did not vary among the three time periods $(F=1.116, d f=4, p=.352)$. The non-significant interaction between the stocked and time period variables suggested that stocking did not affect the levels at which bat activity in general occurred over the course of the survey night, although the power for this test was relatively low $(F=337, d f=2, p=.714$; power $=.103)$. The non-significant phonic group and time period interaction means that the bats in the three phonic categories did not change their activity in different ways during the three time periods $(F$ 
$=1.637, d f=4, p=.493)$. Total bat activity varied significantly $(F=9.385, d f=2, p<$ .001) between time periods; the planned comparisons between Early, Mid, and Late showed that the combined mean of bat activity during the Early and Late periods was significantly greater then the mean activity in the Mid period $(F=6.736, d f=1, p=$ .010 ), and that the mean activity level during the Early period was significantly higher than during the Late period ( $F=12.034, d f=1, p<.001$, Figure 7). Lake pair was found to be a significant block effect, indicating that the blocking parameters (elevation, location, area, and depth) could have significantly impacted results if they were not taken into account $(F=5.905, d f=8, p<.001)$. Lake depth, area, perimeter, and the distance of the lake to the nearest river were assessed as covariates, but none was a significant correlate at the 0.05 level. 

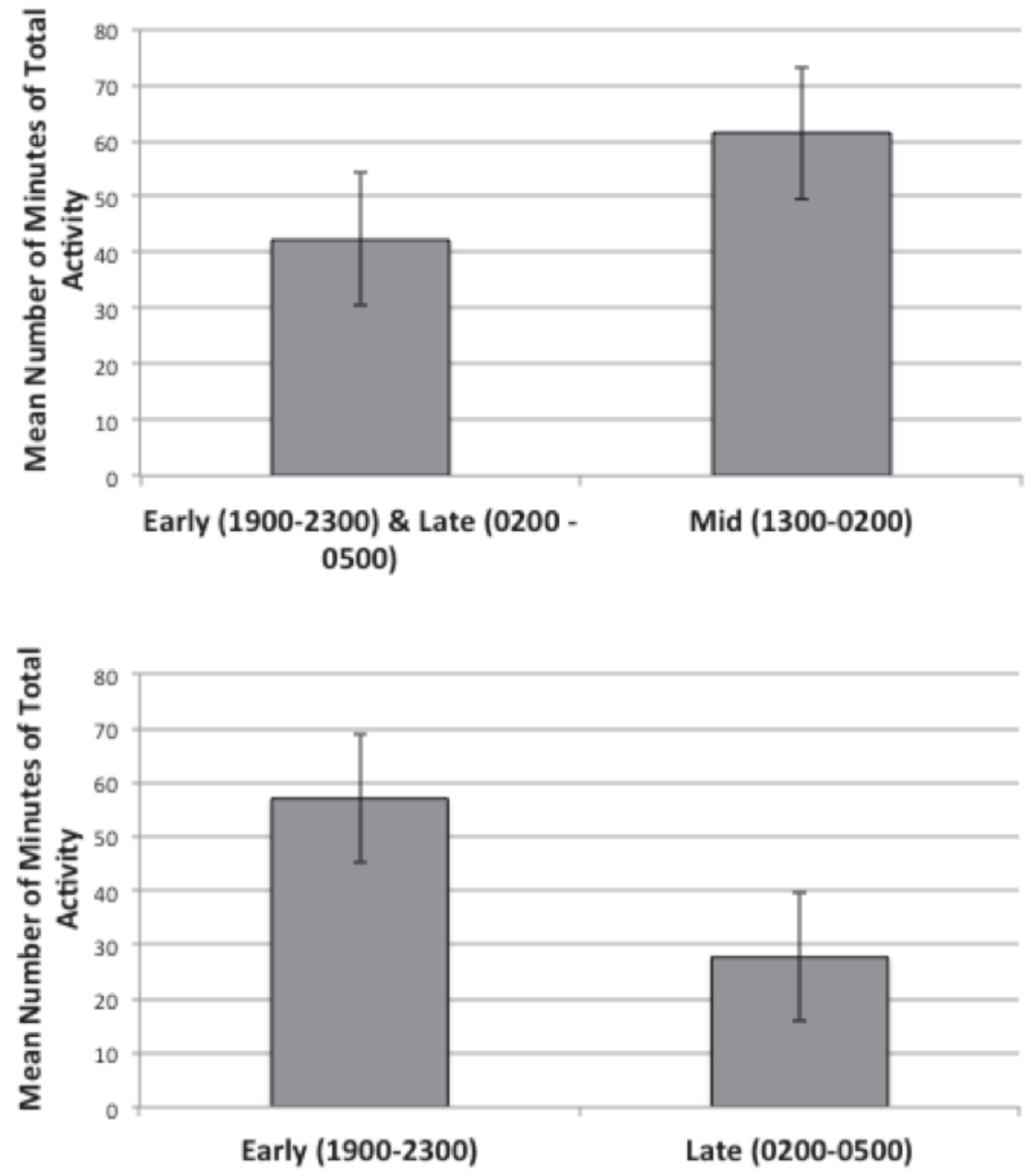

Time Period

Figure 7. Results from planned comparisons: Time period effect for the total activity of bats at surveyed lakes.

The dependent variable is the number of minutes of activity (minutes with echolocation call sequences recorded). The independent variable is time period (Early:1900 - 2300, Mid: 2300 - 0200, Late: 0200-0500). The two planned comparisons for Time Period are included: Early and Late versus Mid, and Early versus Late. Lake pair was used as a block. Time period is in military time. Confidence bars are $95 \%$. 
A three-way ANCOVA showed that levels of foraging activity differed among the three phonic groups at stocked and unstocked lakes and among the three time periods (Table 2).

Table 2. 3-Way ANCOVA for the foraging activity of bats at surveyed lakes.

\begin{tabular}{lrrrrr} 
Source & $d f$ & Mean Square & $F$ & $p$-value & Observed Power \\
\hline Stocked & 1 & 55.749 & .068 & N/A & .058 \\
Phonic Group & 2 & 16451.747 & 20.092 & N/A & 1.000 \\
Time Period & 2 & 4808.173 & 5.872 & N/A & .868 \\
Lake Pair & 8 & 4726.137 & 5.772 & $<.001$ & 1.000 \\
Area & 1 & 5492.457 & 6.708 & .011 & .730 \\
Distance to Nearest & 1 & 3259.742 & 3.981 & .048 & .508 \\
River & & & & & .996 \\
Stocked * Phonic Group & 2 & 10251.463 & 12.520 & $<.001$ & .772 \\
Phonic Group * Time & 4 & 2379.164 & 2.906 & .024 & .237 \\
Period & & & & & .300 \\
Stocked * Time Period & 2 & 888.667 & 1.085 & .341 & .428 \\
Stocked * Phonic Group & 4 & 791.102 & .966 & &
\end{tabular}

Note: Dependent variable is the number of minutes of foraging activity (minutes with feeding buzzes recorded). Independent variables are stocked (yes or no), phonic group ( $25 \mathrm{kHz}, 40 \mathrm{kHz}$, and $50 \mathrm{kHz}$ ), and time period (Early: 1900 - 2300, Mid: 2300 0200, Late: 0200-0500). Lake pair was used as a block. Lake area and the distance of the lake to the nearest river were significant covariates. Significant $p$-values are emphasized in bold italics.

The significant stocked and phonic group interaction $(F=12.520, d f=2, p<.001)$ indicated that foraging activity for each of the three phonic groups of bats varied in response to stocked trout in the lakes; bats in the $40 \mathrm{kHz}$ phonic group had higher foraging activity at lakes with stocked trout, bats in the $50 \mathrm{kHz}$ phonic group showed a 
slight increase in foraging activity at stocked lakes, but the $25 \mathrm{kHz}$ group showed no change or slightly higher levels of foraging activity at unstocked lakes (Figure 8).

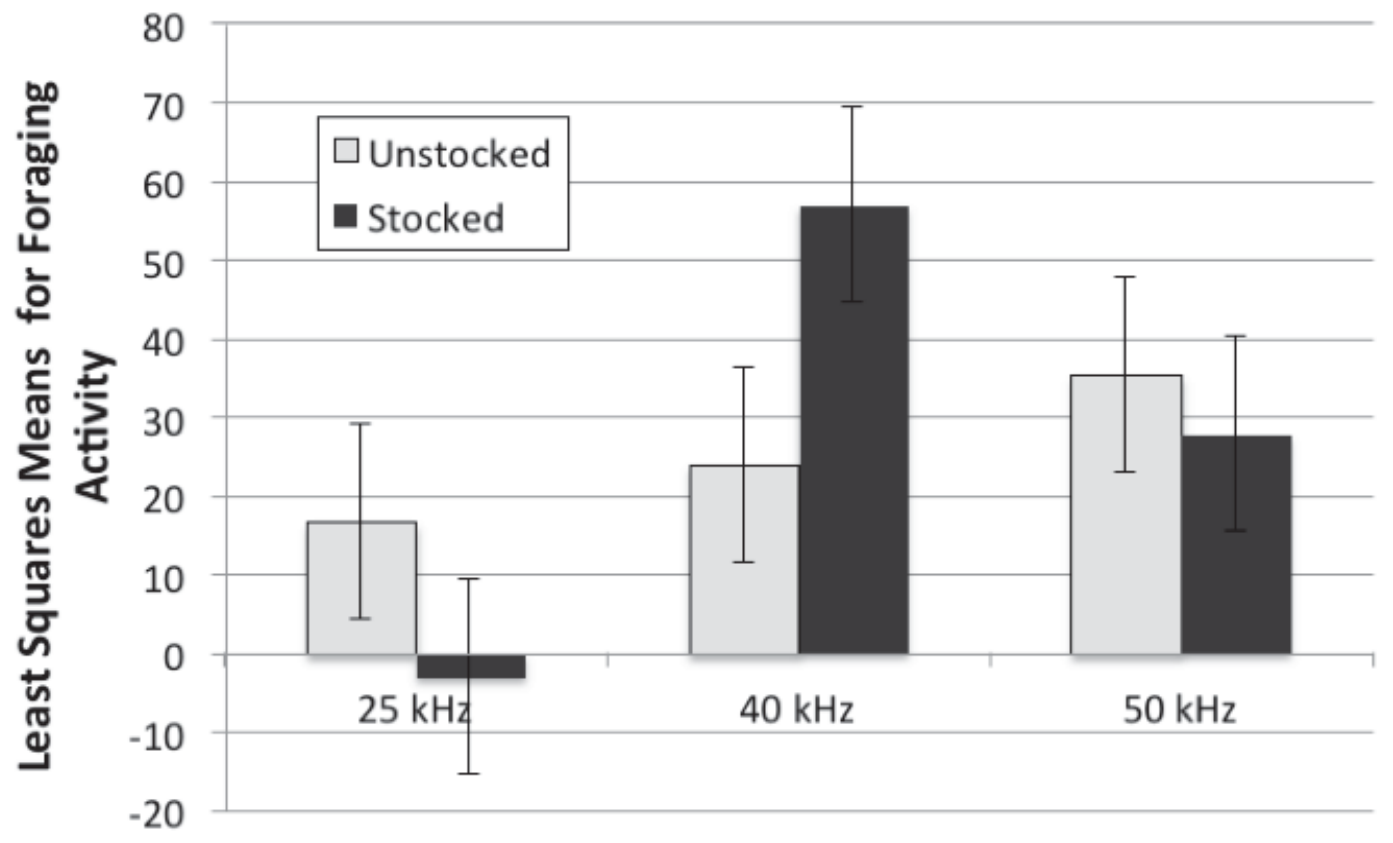

\section{Phonic Group}

Figure 8. Results from 3-way ANCOVA: The significant stocked * phonic group interaction for foraging activity of bats at surveyed lakes.

The data are least squares means adjusted for two covariates: area of the lake and distance of the lake from the nearest river. The dependent variable is the number of minutes of foraging activity (minutes with feeding buzzes recorded). Independent variables are stocked (yes or no) and phonic group ( $25 \mathrm{kHz}, 40 \mathrm{kHz}$, and $50 \mathrm{kHz}$ ). Lake pair was used as a block. Confidence bars are $95 \%$.

In addition, the significant interaction between phonic group and time period $(F=2.906$, $d f=4, p=.024)$ showed that the three phonic groups of bats have different patterns of foraging activity over the course of the night; the highest levels of $40 \mathrm{kHz}$ foraging activity occurred in the Early and Mid time periods (1900 - 2300 hours and $2300-0300$ hours), the highest levels of $50 \mathrm{kHz}$ foraging activity occurred in the Mid time period 
(2300 - 0300 hours) and levels of foraging activity for the $25 \mathrm{kHz}$ group did not change significantly throughout the night (Figure 9).

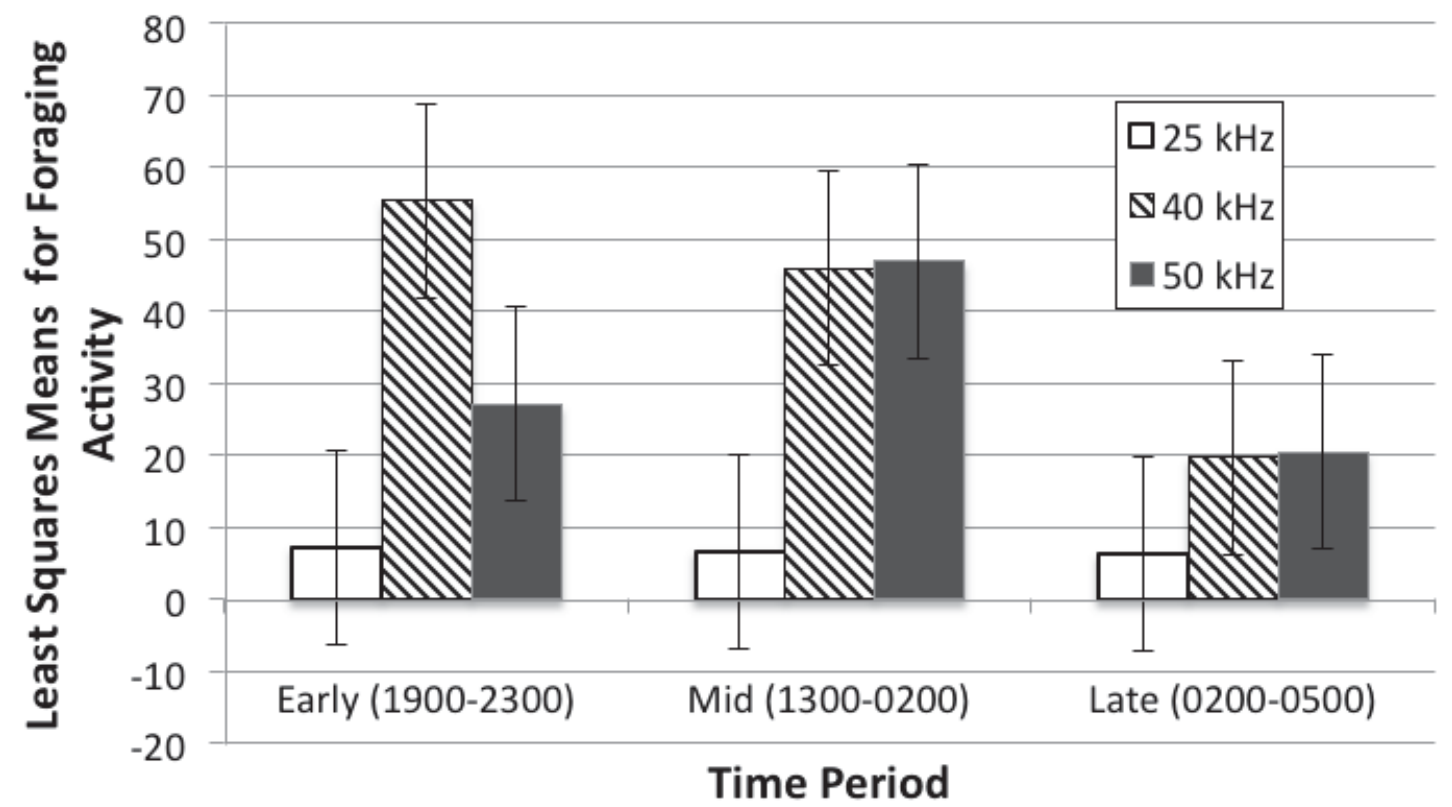

Figure 9. Results from 3-way ANCOVA: The significant phonic group * time period interaction for foraging activity of bats at surveyed lakes.

The dependent variable is the number of minutes of foraging activity (minutes with feeding buzzes recorded). The independent variable is time period (Early: $1900-2300$, Mid: 2300 - 0200, Late: 0200-0500). Time period is in military time. The data are least squares means adjusted for two covariates: area of the lake and distance of the lake from the nearest river. Confidence bars are $95 \%$.

The non-significant Stocked*Time Period*Phonic Group interaction implied that the responses of the three phonic groups to stocking did not vary significantly among the three time periods $(F=.966, d f=4, p=.428)$. The non-significant interaction between the stocked and time period variables $(F=1.085, d f=2, p=.341)$ suggested that stocking did not influence the time period in which the foraging activity of all bats occurred, although the power for this test was relatively low (power $=.237$ ). Lake pair was found to 
be a significant block effect $(F=5.772, d f=8, p<.001)$, which indicated that the blocking parameters (elevation, location, area, and depth) could have significantly impacted results if they were not taken into account. There was a slight, positive correlation between lake area and the amount of feeding activity $(r=.201, n=162, p<$ $.05)$, while there was a slightly negative correlation between foraging activity at a lake and the distance of that lake from the nearest river $(r=-.083, n=162, p<.01)$.

A three-way ANOVA showed that foraging effort among the three phonic groups varied with respect to whether or not the lakes were stocked but did not vary among time periods (Table 3).

Table 3: 3-Way ANOVA for the foraging effort of bats at surveyed lakes.

\begin{tabular}{|c|c|c|c|c|c|}
\hline Source & Df & $\begin{array}{l}\text { Mean } \\
\text { Square }\end{array}$ & $\mathrm{F}$ & $P$ value & Observed Power \\
\hline Stocked & 1 & .080 & 2.078 & N/A & .299 \\
\hline Phonic Group & 2 & 2.275 & 59.428 & N/A & 1.000 \\
\hline Time Period & 2 & .048 & 1.249 & .290 & .268 \\
\hline Lake Pair & 8 & .173 & 4.531 & $<.001$ & .996 \\
\hline Stocked * Phonic Group & 2 & .140 & 3.653 & .029 & .664 \\
\hline Phonic Group * Time & 4 & .036 & .931 & .448 & .289 \\
\hline \multicolumn{6}{|l|}{ Period } \\
\hline Stocked $*$ Time Period & 2 & .029 & .757 & .471 & .176 \\
\hline $\begin{array}{l}\text { Stocked * Phonic Group } \\
* \text { Time Period }\end{array}$ & 4 & .032 & .831 & .508 & .260 \\
\hline Error & 129 & .038 & & & \\
\hline
\end{tabular}

Note: Dependent variable is the ratio of the number of minutes of activity to the number of minutes of foraging activity. Independent variables are stocked (yes or no), phonic group ( $25 \mathrm{kHz}, 40 \mathrm{kHz}$, and $50 \mathrm{kHz}$ ), and time period (Early: 1900 - 2300, Mid: 2300 - 0200, Late: 0200-0500). Lake pair was used as a block. Lake depth, area, perimeter, and the distance of the lake to the nearest river were initially included as covariates, but were not significant and were not included. Significant $p$-values are emphasized in bold italics. 
The significant stocked and phonic group interaction $(\mathrm{F}=3.653, \mathrm{df}=2, \mathrm{p}=.029)$ indicated that the presence of stocked fish caused different reactions among the phonic groups: $25 \mathrm{kHz}$ bats had a slight increase in foraging effort at lakes that did not have stocked trout, $40 \mathrm{kHz}$ bats increased their foraging effort substantially at lakes with stocked trout, and $50 \mathrm{kHz}$ bats show almost no change (Figure 10).

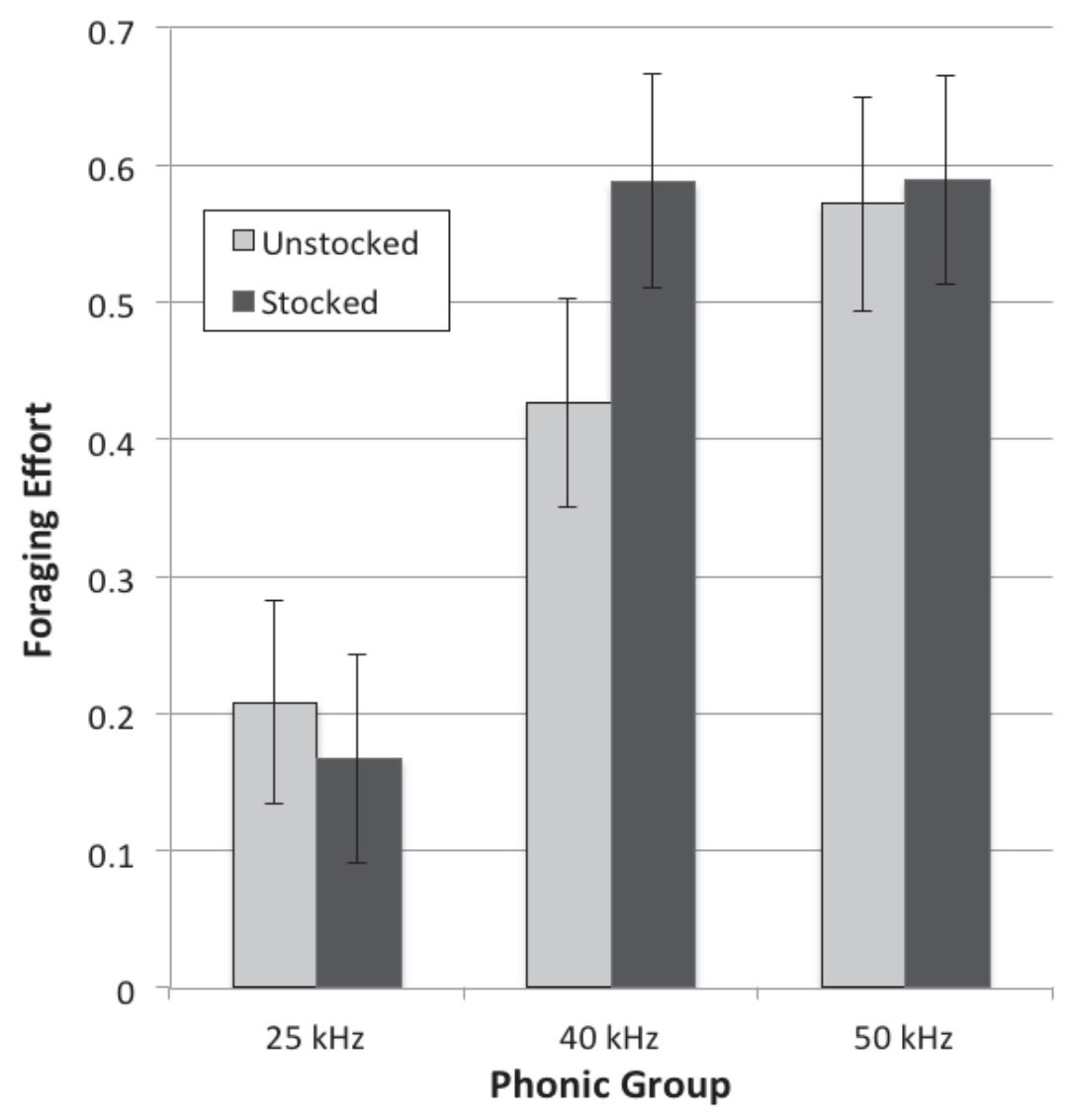

Figure 10. Results from 3-way ANOVA: The significant stocked * phonic group interaction for foraging effort of bats at surveyed lakes.

The dependent variable is the ratio of the number of minutes of foraging activity to the number of minutes of total activity. Independent variables are stocked (yes or no) and phonic group $(25 \mathrm{kHz}, 40 \mathrm{kHz}$, and $50 \mathrm{kHz})$. Lake pair was used as a block. Confidence bars are $95 \%$. 
The non-significant Stocked*Phonic Group*Time Period interaction $(F=1.249, d f=2, p$ $=.290$ ) indicated the responses of the three phonic groups to stocking did not vary significantly among the three time periods $(F=.831, d f=4, p=.508)$. The nonsignificant interaction between the time period and the stocking variable $(F=.471 . d f=2$, $p=.176$ ) implied that stocked trout do not affect the level of foraging effort for bats as a whole over the course of the night $(F=.757, d f=2, p=.471)$. The non-significant interaction between time period and phonic group means that the bats in my three phonic categories don't change their foraging effort in significantly different ways during the three time periods $(F=.931, d f=4, p=.448)$. Overall, foraging effort did not vary between time periods $(F=1.249 . d f=2, p=.290)$; while the power is relatively low (power $=.268$ ), the $\mathrm{p}$-value is much higher than 0.05 so it is likely that there is no real difference. Lake pair was found to be a significant block effect, indicating that the blocking parameters (elevation, location, area, and depth) could have significantly impacted results if they were not taken into account $(F=4.531, d f=8, p<.001)$. Lake depth, area, perimeter, and the distance of the lake to the nearest river were assessed as covariates, but none was a significant correlate at the 0.05 level.

The ANCOVA suggested that stocking did not appear to change the abundances of insect orders at the study lakes (Table 4$)$. The stocked effect was not significant $(F=$ 2.111, $d f=1, p=.203$ ) which indicated that the relationship between small dipterans and large aquatic insects did not differ between stocked and unstocked lakes. However, the frequencies for insect captures were very low (Table 5) and the extremely low power of 
this analysis (power $=0.203$ ) indicates that a larger sample size and higher capture rates are needed to address this question.

Table 4: ANCOVA for the ratio of small ( $<3 \mathrm{~mm}$ ) Dipterans to larger aquatic insects caught at lakes with and without stocked trout.

\begin{tabular}{lrrrrr} 
Source & Df & $\begin{array}{r}\text { Mean } \\
\text { Square }\end{array}$ & F & P value & Observed Power \\
\hline Stocked & 1 & 2.642 & 2.111 & .220 & .203 \\
Lake Pair & 8 & 15.884 & 12.694 & .013 & .927 \\
Perimeter & 1 & 14.317 & 11.442 & .028 & .718 \\
Area & 1 & 15.668 & 12.522 & .024 & .754 \\
Depth & 1 & 16.159 & 12.914 & .023 & .766 \\
Error & 4 & 1.251 & & &
\end{tabular}

Note: Dependent variable is the number of small Dipterans divided by the number of Ephemeropterans and Trichopterans caught at lakes. The independent variable is stocked (yes or no). Lake pair was used as a block. Lake perimeter, area, and depth were significant covariates. Significant $p$-values are emphasized in bold italics.

Table 5: Capture frequencies for three orders of insects at stocked and unstocked lakes.

\begin{tabular}{|c|c|c|c|}
\hline \multicolumn{4}{|c|}{ Stocked Lakes } \\
\hline Pair & Diptera $(<3 \mathrm{~mm})$ & Ephemeroptera & Trichoptera \\
\hline 1 & 42 & 0 & 10 \\
\hline 2 & 57 & 0 & 6 \\
\hline 3 & 63 & 0 & 4 \\
\hline 4 & N/A & N/A & $\mathrm{N} / \mathrm{A}$ \\
\hline 5 & $\mathrm{~N} / \mathrm{A}$ & N/A & $\mathrm{N} / \mathrm{A}$ \\
\hline 6 & N/A & N/A & $\mathrm{N} / \mathrm{A}$ \\
\hline 7 & 21 & 0 & 0 \\
\hline 8 & 34 & 1 & 0 \\
\hline 9 & 3 & 0 & 0 \\
\hline Mean & 36.7 & 0.2 & 3.3 \\
\hline
\end{tabular}




\begin{tabular}{|c|c|c|c|}
\hline \multicolumn{4}{|c|}{ Unstocked Lakes } \\
\hline Pair & Diptera $(<3 \mathrm{~mm})$ & Ephemeroptera & Trichoptera \\
\hline 1 & 30 & 0 & 2 \\
\hline 2 & 39 & 1 & 4 \\
\hline 3 & 73 & 1 & 4 \\
\hline 4 & $\mathrm{~N} / \mathrm{A}$ & $\mathrm{N} / \mathrm{A}$ & $\mathrm{N} / \mathrm{A}$ \\
\hline 5 & N/A & $\mathrm{N} / \mathrm{A}$ & $\mathrm{N} / \mathrm{A}$ \\
\hline 6 & $\mathrm{~N} / \mathrm{A}$ & $\mathrm{N} / \mathrm{A}$ & $\mathrm{N} / \mathrm{A}$ \\
\hline 7 & 13 & 0 & 2 \\
\hline 8 & 17 & 0 & 0 \\
\hline 9 & 6 & 0 & 0 \\
\hline Mean & 29.7 & 0.3 & 2.0 \\
\hline
\end{tabular}

Note: N/A indicates that samples were lost, damaged, or incomplete at time of analysis; documented rates of insect capture at these sites were consistently low. Other insect orders caught include Odonata and Coleoptera.

\section{Discussion}

Bats change their foraging behavior in response to modifications of aquatic ecosystems that affect their prey base (Abbott et al., 2009; Kalcounis-Rueppel, 2007;

Scott et al., 2010; Vaughan et al., 1996). The results of my study support this conclusion; bats in the $25 \mathrm{kHz}$ (Eptesicus fuscus, Lasiurus cinereus, Lasionycteris noctivagans, Tadarida brasilienses, and Myotis evotis) and the $50 \mathrm{kHz}$ (M. californicus and $M$. yumanensis) categories did not have significant behavioral changes with respect to the trout status of a lake, which implies that the prey base of these bat species is not being impacted by the trout in these lakes. In contrast, bats in the $40 \mathrm{kHz}$ group (M. lucifugus and $M$. ciliolabrum) displayed greater activity at lakes with stocked trout, suggesting that bats in this phonic group use the kinds of insects that are present at lakes with trout. Since $M$. lucifugus is very active over aquatic habitats, forages on aquatic insects, and is 
common above 2,000 feet in the Sierra Nevada, whereas $M$. ciliolabrum is not associated with aquatic habitats and is not common in this area, the majority of calls recorded in the $40 \mathrm{kHz}$ category can likely be attributed to M. lucifugus, indicating that this species showed a strong response to stocked trout (Clare et al., 2011; Ober \& Hayes, 2008; Pierson et al., 2001, Rodriguez \& Ammerman, 2004).

The timing of bat activity changed throughout the night in unexpected ways, but the stocked status of the lakes did not influence the temporal pattern. Bats that depend on crepuscular swarms of insects generally follow a bimodal activity pattern, with a peak at dusk and a second peak at dawn (Hayes, 1997; Rydell et al., 1996); however, in this study, foraging activity for $40 \mathrm{kHz}$ and $50 \mathrm{kHz}$ bats stayed relatively high from sunset to 0200 hours and then dropped off in the early morning. This could be attributed to the fact that all surveys took place at the height of maternity season, when the energetic and logistic demands of lactation mean females will forage for longer periods of time and also return to the roosts several times a night to nurse young (Henry et al., 2002). Activity levels for bats in the $25 \mathrm{kHz}$ category remained constant, and relatively low, throughout the night; bats that feed on insects that do not swarm at dusk or dawn do not tend to follow a bimodal pattern, and any peaks in activity may not have been recorded in this group because most of their foraging takes place away from the lakes (Jones \& Rydell 1994).

Changes in the aquatic environment should not elicit a behavioral response from bats that do not concentrate their foraging on aquatic insects, and this was reflected in the lack of response from bats in the $25 \mathrm{kHz}$ group. E. fuscus, L. cinereus, L. noctivagans, 
and M. evotis prefer prey of terrestrial origin such as Lepidopterans and non-aquatic Coleopterans (Agosta, 2002; Barclay, 1991; Ober \& Hayes, 2008; Rainey et al., 2006). T. brasiliensis is a generalist with a wide diet; although this bat will take advantage of large swarms of aquatic insects, it also appears to prefer large, terrestrial prey (McWilliams, 2005; Whitaker et al., 1996). Relatively low levels of foraging activity coupled with consistent foraging effort indicated that bats in this group were probably pursuing prey that are occasionally present at lakes regardless of fish status. A diet analysis would confirm that the prey base of these bats is not impacted by trout stocking.

Bats in the $40 \mathrm{kHz}$ and $50 \mathrm{kHz}$ group have varied diets and foraging strategies; that a significant response was seen from the $40 \mathrm{kHz}$ group but not the $50 \mathrm{kHz}$ group highlights an issue with grouping bats by echolocation call frequencies and not by feeding guild or species. M. lucifugus $(40 \mathrm{kHz})$ and M. yumanensis $(50 \mathrm{kHz})$ are known to concentrate on emergent aquatic prey (Clare et al., 2011; Ober \& Hayes, 2008). M. californicus $(50 \mathrm{kHz})$ forages along the edges of trees, often at canopy height, where it will opportunistically feed on small insects which may or may not be of aquatic origin (Harvey et al., 2011; Ober \& Hayes, 2008). There are few diet records for $M$. ciliolabrum $(40 \mathrm{kHz})$, but it is known to forage over rocky bluffs and cliffs, and the closely related Myotis leibii, consumes moths, beetles and flies (Johnson et al., 2012; Moosman et al., 2007; Rodriguez \& Ammerman, 2004). M. ciliolabrum probably showed no response to trout presence, but that information was overwhelmed by calls from M. lucifugus. Correspondingly, M. yumanensis, which specializes on emergent aquatic insect prey, may have shifted behavior in response to trout, but that signal was 
lost when mixed with calls from $M$. californicus, which does not. Using a full-spectrum analysis to separate these species from one another should yield more definitive results.

The higher levels of overall activity, foraging activity, and foraging effort from the $40 \mathrm{kHz}$ group of bats at lakes with trout indicated that these lakes provide suitable foraging habitat for at least one of the bat species in this group, most likely M. lucifugus. This could be the result of two alternate scenarios. It may be that at my study sites, the preferred prey base of these bats has remained abundant even in the presence of trout. Alternatively, the results could indicate a decline in the quality of the foraging habitat at lakes with trout, even when the high level of foraging activity at these lakes is taken into account.

Although levels of bat activity in an area can be influenced by proximity to roosts and environmental and landscape features, this study was designed to minimize the impact of those variables, so it is unlikely that the stocked lakes presented higher quality habitat independent of their fish status. My analyses showed that in every case, the lake pair effect was highly significant, which indicates that the pairs of lakes were significantly different from each other in terms of the blocking parameters (elevation, location, area, and depth), and only lake area and the distance of the lake to the nearest river were found to be significant covariates in terms of foraging activity. When these factors were taken into account, bats in the $40 \mathrm{kHz}$ category still showed a response to the presence of trout in lakes.

The significantly higher levels of foraging activity from $M$. lucifugus at stocked lakes suggests that the preferred insect prey of these bats was more abundant at these 
lakes than those without fish. However, studies in mountain ecosystems have consistently shown that Ephemeroptera and Trichoptera are reduced in the presence of trout, often substantially so; Epanchin et al. (2010) found that lakes with fish had almost 98\% fewer mayflies relative to those without fish. For bats that specialize in aquatic ecosystems, ephemeropterans and trichopterans are important prey items; M. lucifugus (as well as $M$. yumansensis) rely heavily on these insects during the summer breeding season (Anthony \& Kunz, 1977; Clare et al., 2011; Johnston, 2002). Although this study was unable to corroborate this trend due to insufficient insect data, it is unlikely that the ecosystems of the study lakes would be atypical in their response to trout.

Evidence suggests that $M$. lucifugus exhibited higher levels of foraging activity and foraging effort at lakes with trout because they were consuming large numbers of small insect prey. Finlay and Vredenburg (2007), Knapp et al. (2007), and Pope et al. (2009) found increased abundance of small $(<3 \mathrm{~mm})$ dipterans at lakes with trout, and these are known prey of M. lucifugus (Anthony \& Kunz, 1977; Clare et al., 2011; Ober \& Hayes, 2008). Foraging effort (feeding buzzes per unit of overall activity) indicates the number of prey items taken in a given time period; because a higher number of small prey than of large prey are needed to satisfy energy requirements, a bat hunting relatively small insects will exhibit greater foraging effort than a bat eating higher-calorie insects (Gonsalves, 2013).

It is unknown whether abundant small dipterans represent a high-quality prey base for M. lucifugus, or if scarcity of larger, preferred prey is driving compensatory feeding on smaller prey (Cruz-Rivera \& Hay, 2000). Optimal foraging theory predicts 
that relatively unprofitable prey items will be included in a predator's diet only as more profitable prey becomes unavailable (Davies, 1977), but some studies have found that the inclusion of small prey items is positively correlated with their abundance (Turner, 1982). The relative abundance and swarming behavior of small dipterans will decrease the amount of energy bats spend pursuing them; however, this may not offset their small size; Turner et al. (1982) showed that the inclusion of many small items in the diet of foraging swallows resulted in a decrease in their energy gain rate.

In order to implement meaningful conservation strategies for bats in the Sierra Nevada, it is important to decisively establish whether small dipterans are the prey base for aquatic insect specialists at lakes with stocked fish, as the results of this study suggest, and, if so, whether this situation represents a cost to those bats. Finlay and Vredenburg (2007) found that, due to the lack of large-bodied ephemeropterans and trichopterans and in spite of higher numbers of small dipterans, the biomass of emergent insects from lakes with trout was 19 times lower than the biomass flux at trout-free lakes; with such reduced biomass, bats may be unable to satisfy their energetic needs. A dietary study of the of $M$. lucifugus guano in these areas would reveal the actual consumed prey, and an analysis of the caloric content of those prey items would show whether bats are able to meet their energy requirements.

This is especially important for bats under the increased energetic demands of pregnancy and lactation (Kurta et al., 1989). Although dipterans are known prey of $M$. lucifugus, there is evidence that higher-calorie ephemeropterans are the preferred prey base during breeding (Anthony \& Kunz, 1977). In Southwestern Ontario, Clare et al. 
(2011) found that while small dipteran species comprised 63\% of the diet of M. lucifugus during pregnancy, ephemeropterans made up $66 \%$ of their diet during lactation. Consumption of small dipterans by bats in my study area at the height of maternity season (July, when bats are most likely lactating) may be evidence of compensatory feeding driven by the unavailability of more profitable prey, and animals in this situation have been shown to have reduced survivorship, growth, and fecundity (Cruz-Rivera \& Hay, 2000).

The results of this study can inform management decisions; because there is evidence that trout in lakes lower the quality of foraging habitat for some bats, then removal of trout from those systems should benefit affected species. Although $M$. lucifugus is a relatively common and abundant North American bat, eastern U.S. populations of this species have been particularly impacted by white-nosed syndrome (Harvey et al., 2011), and as the syndrome spreads west, conservation or restoration efforts focused on this species may become essential. 


\section{References}

Abbott, I. M., Sleeman, D.P., \& Harrison, S. (2009). Bat activity affected by sewage effluent in Irish rivers. Biological Conservation, 142(12), 2904-2914. doi: http://dx.doi.org/10.1016/j.biocon.2009.07.012

Agosta, S. J. (2002). Habitat use, diet and roost selection by the Big Brown Bat (Eptesicus fuscus) in North America: a case for conserving an abundant species. Mammal Review, 32(3), 179-198. doi:10.1046/j.1365-2907.2002.00103.x

Akasaka, T., Nakano D., \& Nakamura, F. (2009). Influence of prey variables, food supply, and river restoration on the foraging activity of Daubenton's bat (Myotis daubentonii) in the Shibetsu River, a large lowland river in Japan. Biological Conservation, 142(7), 1302-1310.

Anthony, Edythe L. P. \& Kunz, T.H.. (1977). Feeding Strategies of the Little Brown Bat, Myotis Lucifugus, in Southern New Hampshire. Ecology, 54(4), 775-786.

Bahls, P. (1992). The Status of Fish Populations and Management of High Mountain Lakes in the Western United States. Northwest Science, 66(3), 183-193.

Barclay, R. M. R. (1991). Population structure of temperate zone insectivorous bats in relation to foraging behaviour and energy demand. Journal of Animal Ecology, 60 (1), 165-178. doi:10.2307/5452

Benjamin, J. R., Fausch, K. D., \& Baxter, C. V. (2011). Species replacement by a nonnative salmonid alters ecosystem function by reducing prey subsidies that support riparian spiders. Oecologia, 167(2), 503-512.

Bland, R. G., \& Jaques, H. E. (2010). How to know the insects. Waveland Press.

Collier, K., \& Smith, B. (1995). Sticky trapping of adult mayflies, stoneflies and caddisflies alongside three contrasting streams near Hamilton, New Zealand. New Zealand Natural Sciences, (22), 1-9.

Clare, E. L., Barber, B. R., Sweeney, B. W., Hebert, P. D. N., \& Fenton, M. B. (2011). Eating local: influences of habitat on the diet of little brown bats (Myotis lucifugus). Molecular Ecology, 20(8), 1772-80. doi:10.1111/j.1365-294X.2011.05040.x

Cruz-Rivera, E., \& Hay, M. E. (2000). Can quantity replace quality? Food choice, compensatory feeding, and fitness of marine mesograzers. Ecology, 81(1), 201-219 
Davies, N. B. (1977). Prey selection and the search strategy of the spotted flycatcher (Muscicapa striata): A field study on optimal foraging. Animal Behaviour, 25(4), 1016-1033. doi:http://dx.doi.org/10.1016/0003-3472(77)90053-7

Duvergé, P. L., Jones, G., Rydell, J., \& Ransome, R. D. (2000). Functional significance of emergence timing in bats. Ecography, 23(1), 32-40.

Downs, N. C., \& Racey, P. A. (2006). The use by bats of habitat features in mixed farmland in Scotland. Acta Chiropterologica, 8(1),169-185 doi:10.3161/17335329(2006)8[169:TUBBOH]2.0.CO;2

Epanchin, P. N., Knapp, R. A., \& Lawler, S. P. (2010). Nonnative trout impact an alpinenesting bird by altering aquatic-insect subsidies. Ecology, 91(8), 2406-2415.

Erickson, J. L., \& West, S. D. 2002. The influence of regional climate and nightly weather conditions on activity patterns of insectivorous bats. Acta Chiropterologica, 4(1), 17-24. doi:10.3161/001.004.0103

Fenton, M. B., Boyle, N. G. H., Harrison, T. M., \& Oxley, D. J. (1977). Activity patterns, habitat use, and prey selection by some African insectivorous bats. Biotropica, 9(2), 73-85.

Finlay, J. C., and Vredenburg, V. T. (2007). Introduced Trout Sever Trophic Connections in Watersheds : Consequences for a Declining Amphibian. Ecology, 88(9), 21872198.

Fukui D., Murakami M., Nakano S., Aoi T. (2006). Effect of emergent aquatic insects on bat foraging in a riparian forest. Journal of Animal Ecology 75(6),1252-1258.

Furlonger, C. L., Dewar, H. J., \& Fenton, M. B. (1987). Habitat use by foraging insectivorous bats. Canadian Journal of Zoology, 65(2), 284-288. doi:10.1139/z87044

Griffin, D. R., Webster, F. A., \& Michael, C. R. (1960). The echolocation of flying insects by bats. Animal Behaviour, 8(3), 141-154.

Gonsalves, L., Law, B., Webb, C., \& Monamy, V. (2013). Foraging ranges of insectivorous bats shift relative to changes in mosquito abundance. PloS One, 8(5), e64081. doi:10.1371/journal.pone.0064081

Google Earth. (2009). Version 5.1.3533.1731 (Software). Mountain View, CA: Google Inc. Accessed 2013. 
Hagen, E. M., \& Sabo, J. L. (2011). A landscape perspective on bat foraging ecology along rivers: does channel confinement and insect availability influence the response of bats to aquatic resources in riverine landscapes? Oecologia, 166(3), 751-60. doi:10.1007/s00442-011-1913-4

Harvey, M. J., Altenbach, J. S., \& Best, T. L. (2011). Bats of the United States and Canada. Johns Hopkins University Press, Baltimore.

Hayes, J. P. (1997). Temporal variation in activity of bats and the design of echolocationmonitoring studies. Journal of Mammalogy, 78(2), 514-524.

Henry, M., Thomas, D. W., Vaudry, R., \& Carrier, M. (2002). Foraging distances and home range of pregnant and lactating little brown bats (Myotis lucifugus). Journal of Mammalogy, 83(3), 767-774.

Johnson, J. S., Dodd, L. E., Kiser, J. D., Peterson, T. S., \& Watrous, K. S. (2012). Food habits of Myotis leibii along a forested ridgetop in West Virginia. Northeastern Naturalist, 19(4), 665-672.

Johnston, D. S. (2002). Data collection protocol: Yuma bat (Myotis yumanensis). Wetlands Regional Monitoring Program Plan, Part 2: Data Collection Protocols:16.

Jones, G., \& Rydell, J. (1994). Foraging strategy and predation risk as factors influencing emergence time in echolocating bats. Philosophical Transactions of the Royal Society of London. Series B: Biological Sciences, 346(1318 ), 445-455. doi:10.1098/rstb.1994.0161

Joseph, M. B., Piovia-Scott, J., Lawler, S. P., \& Pope, K. L. (2011). Indirect effects of introduced trout on Cascades frogs (Rana cascadae) via shared aquatic prey. Freshwater Biology, 56(5), 828-838. doi:10.1111/j.1365-2427.2010.02529.x

Kalcounis-Rueppell, M. C., Payne, V. H., Huff, S. R., and Boyko, A. L. (2007). Effects of wastewater treatment plant effluent on bat foraging ecology in an urban stream system. Biological Conservation, 138(1-2), 120-130. doi:10.1016/j.biocon.2007.04.009

Keinath, D. A. (2004). Anabat call key for the Greater Yellowstone Ecosystem. Wyoming Natural Diversity Database, University of Wyoming, Laramie, Wyoming.

Knapp, R. A. (1996). Non-native trout in natural lakes of the Sierra Nevada: an analysis of their distribution and impacts on native aquatic biota. In Sierra Nevada ecosystem project: final report to Congress (Vol. 3, pp. 363-407). 
Knapp, R. A., \& Matthews, K. R. (2000). Non-Native Fish Introductions and the Decline of the Mountain Yellow-Legged Frog from within Protected Areas.Conservation Biology, 14(2), 428-438.

Knapp, R. A., Matthews, K. R., \& Sarnelle, O. (2001). Resistance and Resilience of Alpine Lake Fauna to Fish Introductions. Ecological Monographs, 71(3), 401-421.

Kurta A, Bell G.P, Nagy K.A, Kunz T.H. (1989). Energetics of pregnancy and lactation in free-ranging little brown bats (Myotis lucifugus). Physiological Zoolology 62(3), 804-818.

Lawler, S. P., \& Pope, K. L. (2006). Non-native fish in mountain lakes: effects on a declining amphibian and ecosystem subsidy. University of California Water Resources Center.

Matthews, K. R., \& Knapp, R. A. (2002). Garter snake distributions in high-elevation aquatic ecosystems : Is there a link with declining amphibian populations and nonnative trout introductions? Journal of Herpetology, 36(1), 16-22.

McWilliams, L. A. (2005). Variation in diet of the Mexican Free-Tailed Bat (Tadarida brasiliensis Mexicana). Journal of Mammalogy, 86(3), 599-605. doi:10.1644/15451542(2005)86[599:VIDOTM]2.0.CO;2

Miller, B. (2001). A method for determining relative activity of free flying bats using a new activity index for acoustic monitoring. Acta Chiropterologica, 3(1), 93-105.

Moosman Jr, P. R., Thomas, H. H., \& Veilleux, J. P. (2007). Food habits of eastern small-footed bats (Myotis leibii) in New Hampshire. The American Midland Naturalist, 158(2), 354-360.

Ober, H. K., and Hayes, J. P. (2008). Prey selection by bats in forests of western Oregon. Journal of Mammalogy, 89(5), 1191-1200.

O'Farrell, M. J., Miller, B. W., \& Gannon, W. L. (1999). Qualitative identification of free-flying bats using the Anabat detector. Journal of Mammalogy, 80(1) 11-23.

Pierson, E. D., W. E. Rainey, and C. J. Corben. (2001). Seasonal patterns of bat distribution along an altitudinal gradient in the Sierra Nevada. Contract report for California Department of Transportation, California State University at Sacramento Foundation, Yosemite Association, and Yosemite Fund. 67pp.

Pilliod, D. S., \& Peterson, C. R. (2001). Local and landscape effects of introduced trout on amphibians in historically fishless watersheds. Ecosystems, 4(4), 322-333. 
Pister, E. P. (2001). Wilderness fish stocking: history and perspective. Ecosystems, 4(4), 279-286

Pope, K. L., Piovia-Scott, J., \& Lawler, S. P. (2009). Changes in aquatic insect emergence in response to whole-lake experimental manipulations of introduced trout. Freshwater Biology, 54(5), 982-993. doi:10.1111/j.1365-2427.2008.02145.x

Rainey, W. E., Power, M. E., \& Clinton, S. M. (2006). Temporal and spatial variation in aquatic insect emergence and bat activity in a restored floodplain wetland. Consumnes Research Group contract report on terrestrial aquatic linkages.

Rodriguez, R. M., \& Ammerman, L. K. (2004). Mitochondrial DNA divergence does not reflect morphological difference between Myotis californicus and Myotis ciliolabrum. Journal of Mammalogy, 85(5), 842-851.

Rydell, J., Entwistle, A., \& Racey, P. (1996). Timing of foraging flights of three species of bats in relation to insect activity and predation risk. Oikos, 76(2), 243-252. doi: $10.2307 / 3546196$

Scott, S. J., McLaren, G., Jones, G., \& Harris, S. (2010). The impact of riparian habitat quality on the foraging and activity of pipistrelle bats (Pipistrellus spp.). Journal of Zoology, 280(4), 371-378. doi:10.1111/j.1469-7998.2009.00670.x

Seidman, V. M., \& Zabel, C. J. (2001). Bat activity along intermittent streams in Northwestern California. Journal of Mammalogy, 82(3), 738-747.

Szewczak, J.M., A. Corcoran, J.P. Kennedy, T.J. Weller, P.C. Orsmbee. 2008. Echolocation call characteristics of Pacific Northwest bats. Paper presented during the proceedings of the Bat Conservation International Acoustic Monitoring Workshop. Tulelake, California, USA.

Storer, T. I., Usinger, R. L., \& Lukas, D. (2004). Sierra Nevada natural history. University of California Press.

Turner, A. K. (1982). Optimal foraging by the swallow (Hirundo rustica): Prey size selection. Animal Behaviour, 30(3), 862-872.

Tyler, T., Liss, W. J., Ganio, L. M., Larson, G. L., Hoffman, R., Deimling, E., \& Lomnicky, G. (1998). Interaction between introduced trout and larval salamanders (Ambystoma macrodactylum) in high-elevation lakes. Conservation Biology, 12(1), 94-105. doi:10.1111/j.1523-1739.1998.96274.x 
Waters, D. A., Rydell, J., \& Jones, G. (1995). Echolocation call design and limits on prey size: a case study using the aerial-hawking bat Nyctalus leisleri. Behavioral Ecology and Sociobiology, 37(5), 321-328.

Whitaker, J. O., Neefus, C., \& Kunz, T. H. (1996). Dietary variation in the mexican freetailed bat (Tadarida brasiliensis mexicana). Journal of Mammalogy, 77, 716-724. doi:10.2307/1382676

Vaughan, N., Jones, G., \& Harris, S. (1996). Effects of sewage effluent on the activity of bats (Chiroptera: Vespertilionidae) foraging along rivers. Biological Conservation, 78(3), 337-343. doi:10.1016/S0006-3207(96)00009-2

Zar, J. H. (1999). Biostatistical analysis. Pearson Education India. 